ISSN 2236-0859

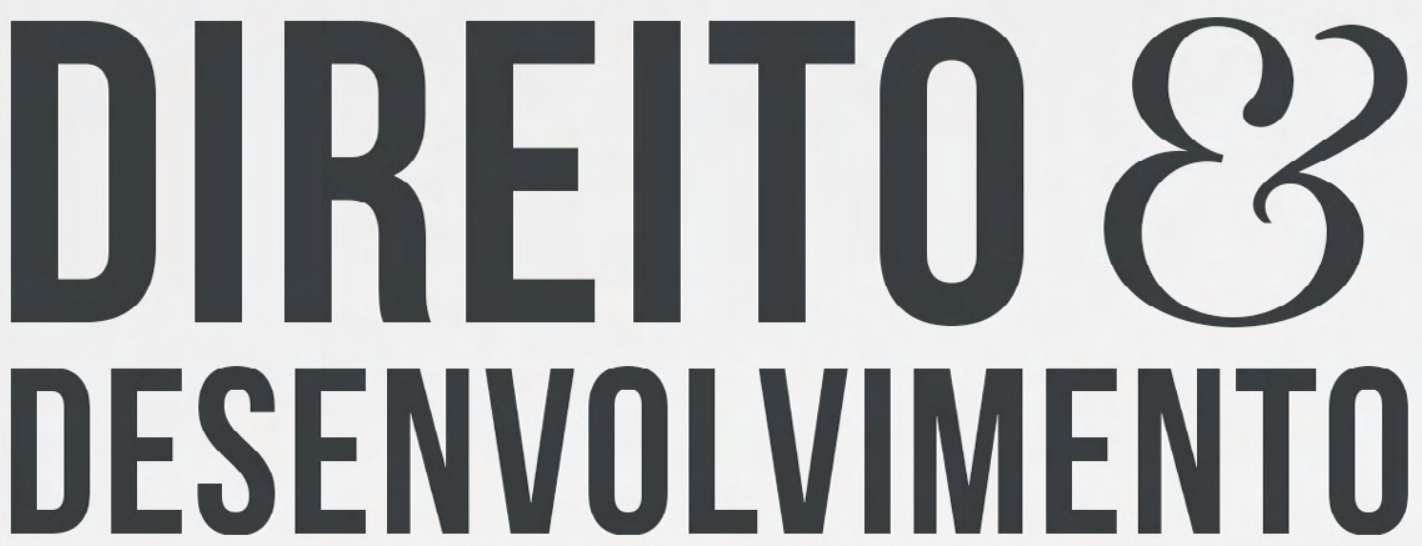

REVISTA DO PROGRAMA DE PÓS-GRADUAÇ̃̃O EM DIREITO MESTRADO EM DIREITO E DESENVOLVIMENTO SUSTENTÁVEL

\title{
ANÁLISE DOS SMART CONTRACTS À LUZ DO PRINCÍPIO DA FUNCGÃO SOCIAL DOS CONTRATOS NO DIREITOBRASLLEIRO
}

ANTONIO CARLOS EFING

ADRIELLY PINHO DOS SANTOS 


\title{
ANÁLISE DOS SMART CONTRACTS À LUZ DO PRINCÍPIO DA FUNÇÃO SOCIAL DOS CONTRATOS NO DIREITO BRASILEIRO
}

\author{
ANALYSIS OF SMART CONTRACTS TROUGHT THE \\ PRINCIPLE OF THE SOCIAL FUNCTION OF CONTRACTS IN \\ BRAZILIAN LAW
}

Recebido: 25/06/2018

Aprovado: 03/10/2018

\author{
Antonio Carlos Efing* \\ Adrielly Pinho dos Santos**
}

RESUMO: Smart contracts são criados por meio de códigos computacionais para execução automática de seus termos após a implementação da condição avençada pelas partes. Apresentam-se como fruto da Revolução Tecnológica, especialmente com o advento da internet e ganham relevância no mundo negocial após o surgimento da tecnologia blockchain, a qual permite o armazenamento dos códigos em cadeia de blocos, reduzindo os custos de execução contratual. Assim, os códigos que dão origem aos contratos inteligentes serão autoexecutáveis, autoaplicáveis e obrigatórios, e nada poderá interferir na produção dos efeitos jurídicos avençados pelas partes. São inúmeros desafios jurídicos impostos à realização dos smart contracts no Brasil, principalmente, porque inexistem leis específicas para tutela desta inovação contratual. A pesquisa buscou verificar a existência de obstáculos a execução destes contratos, à luz do princípio da função social dos contratos, por tratar-se norma principiológica cuja aplicação é indispensável a garantia do equilíbrio entre as partes durante todas as fases contratuais. Constatou-se, por meio do método dedutivo e procedimento monográfico, que as próprias características dos smart contracts executados em blockhain, obstam a efetividade das garantias inerentes ao princípio da função social, ante a irreversibilidade dos efeitos jurídicos produzidos, evidenciando, pois, a relevância do tema para a ciência jurídica.

Palavras-chave: Tecnologia. Contratos eletrônicos. Smart Contracts. Função social.

\begin{abstract}
Smart contracts are created by computacional code to automatically execution of your terms after implementation of condition established parties' established. It presents like an Technological Revolution outcome especially with the advent of internet and it gain relevance at business world after the emergence of blockchain technology, that allows the storage in a block chain with reducing the contractual execution costs. Thus, the codes that give rise to smart contracts are self-executing, self-enforcing and mandatory and anything will not could interfere on legal effects production agreed by the parties. It is innumerable the legal challenges imposes to smart contracts realization's at Brasil, mainly because there are'nt especifics laws to protects this contractual innovation. The research intented verifying if there are obstacles to smart contracts execution under consideration of contracts social function principle because it's a basic norm such application's is indispensable to the warrant of equation between the parties during all contracts phases. It was verify, using deductive method and monographic procedure, that the own characteristics of the smart contracts executated on blockchain, it obstructs the

\footnotetext{
* Doutorado em Direito pela Pontifícia Universidade Católica de São Paulo (200o) e Mestrado em Direito pela Pontifícia Universidade Católica de São Paulo (1996). Atualmente é professor titular da Pontifícia Universidade Católica do Paraná (PUCPR). E-mail: ace@ eradv.com.br

** Mestranda em Direito Socioambiental da Pontifícia Universidade Católica do Paraná (PUCPR), com prêmio Marcelino Champagnat. Advogada em Silvio Fazolli Advogados. Intercâmbio com bolsa SANTANDER para a Universidade de Coimbra (2015). Bolsista em Iniciação Científica da Pontifícia Universidade Católica do Paraná (2013) e da Fundação Araucária (2014). E-mail: adrielly_pinho@hotmail.com
} 
effectiveness of the inherent warrants to the social function principle, against produced legal efeccts irreeversibility which evincing the subject relevance for Law Science.

Keywords: Tecnology. Eletronic contracts. Smart contracts. Social function principle.

\section{INTRODUÇÃO}

Os negócios jurídicos celebrados na sociedade moderna sofrem, constantemente, os impactos das inovações tecnológicas. Para atender os anseios econômicos dos indivíduos, os tradicionais métodos comerciais perdem espaço para as negociações eletrônicas, as quais se apresentam cada vez mais aprimoradas.

O Direito não poderia ficar alheio a tantas transformações sociais e econômicas, de modo que, emergem perante o sistema jurídico brasileiro inúmeros desafios, marcadamente complexos e jamais enfrentado em outro momento da história das sociedades.

Neste contexto, considerando a relação entre tecnologia, aprimoramento dos meios negociais e implicações jurídicas, destaca-se, neste estudo, a emergência dos smart contracts no Brasil, enquanto inovação contratual que impõe severas modificações na forma de contratação e especialmente, no modo de execução das obrigações pactuadas.

\footnotetext{
Os Smart contratcs são contratos desenvolvidos por programas computacionais, que determinam a execução de determinada atividade, no momento em que implementada a condição estipulada pelos contraentes. Caracterizam-se pela capacidade de autoexecutabilidade e auto-aplicabilidade (BASHIR, 2017, p. 199).
}

Tais contratos ganham relevância no mercado negocial, especialmente, após o surgimento da tecnologia blockchain que permite, por meio de uma cadeia de blocos, o armazenamento dos códigos computacionais que dão origem aos smart contracts (GATTESCHI et al., 2018, p. o1).

A implementação dos smart contracts em tecnologia blockchain desperta o interesse jurídico e demanda a atenção dos pesquisadores, na medida em que são suscitadas diversas questões quando de sua adequação ao sistema normativo brasileiro, tais como: interpretação judicial de cláusulas instituídas por meio de códigos computacionais; efetividade de decisões judiciais sobre a execução de códigos; proteção de dados pessoais inseridos em tecnologia blockchain; possibilidade de erros de programação, causando lesão às partes, entre outras.

Diante da inexistência de normas específicas para regulamentação dos smart contracts no Brasil, parte-se da premissa de que é indispensável a utilização dos princípios jurídicos contratuais para interpretação e adequação dos contratos inteligentes à realidade brasileira.

Assim, nesta pesquisa, com destaque para o princípio da função social dos contratos, corolário do direito contratual brasileiro, pretende-se responder ao seguinte problema: há obstáculos para implementação dos smart contracts, à luz do princípio da função social dos contratos?

A pesquisa foi realizada por meio do método dedutivo e o procedimento monográfico. No primeiro tópico realizou-se um estudo bibliográfico introdutório acerca da relação complexa entre tecnologia, Direito e relações contratuais, demonstrando a existência de vantagens e desvantagens na interação dos elementos. Na sequência, fez-se uma investigação conceitual a respeito dos smart contracts e da tecnologia blockchain, destacando-se implicações jurídicas gerais. Por fim, no terceiro tópico, foi feita a análise da função social dos contratos, 
aplicando-a ao contexto dos smart contracts, a fim de verificar a existência de obstáculos a sua implementação no Brasil.

\section{A TECNOLOGIA, O DIREITO E AS RELAÇÕES CONTRATUAIS}

Atecnologiaimpõeprofundasmodificações no mododevida daspessoas, proporcionando uma verdadeira "quebra de paradigmas", nos quais, "conceitos como velocidade, acessibilidade, mobilidade, distância e sociabilidade estão em constante modificação" (FREITAS; BATISTA, 2015, p. 3).

Comunidades que outrora viviam isoladas, sem contato e informação sobre outras culturas, hoje podem comunicar-se umas com as outras instantaneamente. Longas distâncias são percorridas em pouco tempo e a um custo muito mais acessível, facilitando, por exemplo, as relações negociais (EFING; FREITAS, 2012, p. 88).

Em verdade, especificamente quanto aos impactos da tecnologia nas relações negociais, admite-se que "a celeridade, a ausência de distância, a comodidade, a facilidade em coletar dados e fazer pesquisas etc." (EFING; FREITAS, 2012, p. 298) especialmente, após o advento da internet, são elementos que contornam uma revolução no modo de circulação de riquezas, em virtude da possibilidade de minimização de custos e maximização de resultados (BRANDÃO; VASCONCELOS, 2013, p. 127). É dizer, em outras palavras, que "as relações negociais encontraram no dinamismo da Internet um favorecimento à criatividade empresarial, o que fomentou o acelerado crescimento e desenvolvimento das contratações eletrônicas" (LEÃO, 2014, p. 6o).

Com efeito, como resultado da Revolução Industrial e Tecnológica e sob influência do crescimento demográfico e da urbanização, as contratações eletrônicas passam a ocupar o espaço do tradicional e milenar modelo comercial, o qual não mais atendia os interesses da sociedade moderna (LÔBO, 2016, p. 22).

As inovações tecnológicas continuam revolucionando as relações jurídicas negociais. Outrora celebrados por meio da subscrição de instrumento físico, negócios jurídicos passam a ser celebrados através da rede mundial de computadores e, dia após dia, ganham mais vertentes e possibilidades, tal como a capacidade de realizar todas as operações negociais por meio de códigos (BHEEMAIAH, 2017, p. 209). De fato, o que antes era visto como impossível e inimaginável, é hoje uma realidade indiscutível.

A despeito dos benefícios experimentados com a inserção de aplicações tecnológicas na área negocial, a busca pelo ganho de capital e pelo aperfeiçoamento interminável, apregoado como o "ideal do progresso" nesta nova era vivida pela sociedade, apresenta riscos e inseguranças (CAPELLA, 1998, p. 25). A tecnologia torna-se, nesta concepção, um "fenômeno de dois gumes" (GIDDENS, 1991, p. 17).

É dizer: "[...] quando o assunto é tecnologia, o binômio, Internet e segurança, nem sempre andam juntos: a virtualização das relações oculta fragilidades dos sistemas de informática que até os dias atuais ainda não são bem compreendidas pelos usuários de um modo geral" (EFING; FREITAS; PACHEN, 2013).

No que tange às relações contratuais, ao mesmo tempo em que a possibilidade de celebrar contratos eletrônicos pode proporcionar uma série de vantagens as partes, como redução de custos, comodidade e rapidez, também geram situações adversas, a exemplo, das "fraudes eletrônicas, estelionatos, perda de materiais, divulgação sem controle de documentos sigilosos, prejuízos materiais e morais oriundos de fatos ocorridos no mundo digital" (EFING; FREITAS; PACHEN, 2013, p. 344). 
Acrescente-se, ainda, como situação alarmante decorrente da expansão da contratação eletrônica, a potencialização do desequilíbrio contratual entre as partes. Especialmente em relações de consumo, com o advento dos contratos eletrônicos de massa, os fornecedores realizam suas negociações por meio de cláusulas gerais predispostas (contratos de adesão), impondo condições abusivas aos consumidores (LÔBO, 2016, p. 23).

São riscos, muitas vezes, incontroláveis e desconhecidos que criam um cenário de insegurança jurídica na sociedade contemporânea, a qual, Beck denomina como Sociedade de Risco (BECK, 2002). Os riscos, segundo o teórico alemão, surgem a partir de decisões tomadas pelas pessoas, empresas, organizações estatais e políticos, amparados sob a falsa ideia de infalibilidade da tecnologia (BECK, 2002, p. 84).

Tal constatação ganha relevância na medida em que, "no ciberespaço, os corpos não interessam - embora o ciberespaço interesse, de forma decisiva e inexorável, para a vida dos corpos" (BAUMAN, 1999, 27), isto é, não se pode mais imaginar como seriam desenvolvidas todas as atividades diárias, sem as facilidades da tecnologia. Segundo BAUMAN (1999, p. 66):

[...] ninguém parece estar no controle agora. Pior ainda - não está claro o que seria, nas circunstâncias atuais, 'ter o controle'. Como antes, todas as iniciativas e ações de ordenação são locais e orientadas para questões específicas; mas não há mais uma localidade com arrogância bastante para falar em nome da humanidade como um todo ou para ser ouvida e obedecida pela humanidade ao se pronunciar. Nem há uma questão única que possa captar e teleguiar a totalidade dos assuntos mundiais e impor a concordância global.

Com efeito, a ciência do Direito, responsável por garantir a harmonia ea segurança social, depara-se diante de um paradigma, qual seja, manter o equilíbrio entre todas as consequências positivas e negativas do desenvolvimento tecnológico com o devido enfrentamento dos decorrentes e complexos desafios jurídicos. Registre-se que:

[...] nunca os operadores do direito expressaram tanto temor e tanta insegurança quanto na atualidade. Se já era difícil acompanhar a evolução legislativa no Brasil e no mundo, agora o jurista tem de se preocupar com as relações jurídicas mais inusitadas, com os acontecimentos mais imprevisíveis, tudo isso numa velocidade espantosa e preocupante. (BRANDÃO; VASCONCELOS, 2013, p. 129).

Como mencionado, a complexidade dos desafios jurídicos negociais emergentes nesta sociedade tecnológica continua em evolução, ao passo que na busca pela comodidade e agilidade no mundo dos negócios, os contratos eletrônicos são constantemente aprimorados, dando razão ao surgimento de problemáticas jurídicas inéditas, as quais o ordenamento não possui respostas imediatas.

Importa salientar que, a evolução contratual é essencial para o desenvolvimento econômico de nações em desenvolvimento, a exemplo do Brasil. Isto, porque, "é o contrato que proporciona a subsistência de toda a gente. Sem ele, a vida individual regrediria, a atividade do homem limitar-se-ia aos momentos primários" (PEREIRA, 2017).

Outrossim, destaca-se que o aspecto econômico do desenvolvimento está atrelado à própria realização dos direitos humanos, conforme Resolução n. 41/128 publicada pela Assembleia Geral da ONU que dá origem a Declaração do Direito ao Desenvolvimento. O direito ao desenvolvimento, então, passa a ser visto como um dos direitos humanos indispensáveis ao indivíduo, de modo que, impõe aos Estados a sua efetivação (MARQUES; OLIVEIRA; SÁTIRO, 2016, p. 178). 
Assim, dentre os inúmeros desafios jurídicos, oriundo desta Sociedade de Risco, relacionados à expansão da atividade contratual eletrônica, destaca-se, nesta pesquisa, os problemas identificados a partir da utilização dos smarts contracts.

\section{SMART CONTRACT: INOVAÇÃO TECNOLÓGICA CONTRATUAL}

Como dito anteriormente, a tecnologia alcança a seara contratual e apresenta ao mundo dos negócios uma gama de modalidades eletrônicas de contratos, buscando atender os interesses econômicos dos agentes.

Os Smart Contract ${ }^{2}$ apresentam-se, dentro deste contexto, como uma inovação tecnológica contratual que impõe modificações relevantes na forma de contratar e especialmente no modo de execução das avenças pactuadas.

Trata-se de um programa de computador escrito em uma linguagem que pode ser lida por outro computador ou máquina e que será executado automaticamente após a realização de certa condição estabelecida em código, sem a intermediação de terceiros (BASHIR, 2017, p. 199).

Simplificando, os smart contracts são criados na conhecida fórmula de programação computacional "se $\mathrm{x}$, então y", isto é, se implementada certa condição, será cumprida a prestação contraposta. Exemplo ilustrativo de smart contract, facilmente percebido, são as máquinas automáticas de venda de refrigerantes. Se, o contratante inserir a máquina o valor $\mathrm{x}$, lhe será entregue o produto y. Ou seja, implementada a condição estabelecida pelo contratado (preço), que será lida pela máquina, em códigos computacionais, tem-se a contraprestação ao contratante (produto).

Por esta razão, diz-se que são regidos pelo princípio de que "the code is law"3. A execução é automaticamente impingida e não há como obstá-la, sendo caracterizados por isso, como autoaplicáveis. Além disso, não podem ser influenciados por fatores externos, pelo que se defende a existência de maior segurança e confiança entre as partes (BASHIR, 2017, p. 199).

Acrescente-se que, os smart contracts podem ser padronizados, tal como um contrato tradicional, de modo que os contraentes poderão optar pelo modelo que melhor se adequa ao negócio objeto de contratação, a exemplo, de troca de imóveis, compra e venda de automóveis, pagamentos de seguros etc. (BHEEMAIAH, 2017, p. 139). Explica-se:

With the use of smart contracts, the firm can then automatically enforce and fulfill the obligations of the parties when the conditions of the contract are met. As a smart contract provides the ability to program a contract, payouts between parties can be made once certain criteria have been met, without involving a middleman. This could also be triggered from input signals that come from IoT devices that are used by the insureds. Just as Discovery uses information that comes from an insured's FitBit device, the same data can be sent to a smart contract in order to execute changes in premium payments as the client's health state changes (BHEEMAIAH, p. 140, 2017). ${ }^{4}$

O conceito de smart contract não é novo. Nos Estados Unidos, desde a década de 1990, existem discussões sobre a sua implementação perante o mundo negocial. Entretanto, com

2 Tradução livre: contrato inteligente.

3 Tradução livre: código é lei.

4 Tradução livre: Com os contratos inteligentes, a empresa pode impor e executar automaticamente as obrigações das partes quando as condições do contrato se realizarem. Tal como um contrato inteligente proporciona a capacidade para programar um contrato, os pagamentos entre as partes podem ser feitos assim que uma certa condição se realize, sem envolvimento de intermediários. Isto poderia também ser desencadeado a partir de sinais de entrada advindos de dispositivos da Internet das Coisas que são usados pelos segurados. Como a Discovery usa informações que advém de dispositivos FitBit, os mesmos dados podem ser enviados para um contrato inteligente para executar o pagamento do prêmio ante a mudança do estado de saúde de um segurado. 
o surgimento da tecnologia blockchain, que proporciona a redução significativa de custos de transação e a simplificação de contratos complexos, o instituto ganha atenção dentre as modalidades contratuais (BASHIR, 2017, p. 198).

A tecnologia blockchain pode ser definida como:

“[...] uma Cadeia de Blocos Eletrônicos Permanentes [...], um engenhoso procedimento tecnológico para armazenamento de dados que envolve um protocolo de confiança e de consenso sobre uma rede, baseado na comunicação e autenticação de registros distribuídos ponto a ponto, comumente chamado de Distributed Ledger Technology (DLT). É construído por ligações criptográficas de blocos no sentido de recrudescer (para alguns garantir) os mecanismos a prova de violação e nesse ponto, inclusive, aos termos inseridos na competência da ilustre comunidade de assinaturas digitais. Não há segredos nos insumos tecnológicos por trás dessa esmerada forma de se registrar de maneira íntegra, com um robusto mecanismo de imutabilidade, um ativo digital, que pode ser conjugada com a legal manifestação de vontade nos documentos e transações eletrônicas (LACERDA, 2017, s.p.).

Em outras palavras, a blockchain armazena e permite controlar todas as transações realizadas dentro da aplicação que serão agrupadas em blocos. Um bloco sempre fará referência ao bloco anterior, de onde advém o termo "cadeia de blocos", e cada rede de computador terá uma cópia local de todos os blocos, evitando, pois, a perda de dados, os quais, ressalte-se, não podem ser alterados ou apagados (GATTESCHI et al, 2018, p. 2-4).

A principal característica da aplicação tecnológica é a descentralização. As operações realizadas dentro da blockchain não dependem da interferência de intermediários, de modo que a validação destas transações é feita por nós em rede, utilizando-se de criptografia, proporcionando, pois, maior confiança as partes (GATTESCHI et al, 2018, p. 8).

Inicialmente, a blockchain foi explorada no setor notarial, para armazenar registros públicos e certidões, proteger propriedade intelectual, provar e/ou certificar a validade de documento e também gravar códigos. Atualmente, porém, já é utilizada para as mais diversas atividades (LACERDA, 2017).

Na concepção de tratamento de códigos, a blockchain associa-se aos smart contracts, intensificando a sua implementação no mundo dos negócios. Criados dentro de uma cadeia de blocos, os smart contracts são armazenados, por meio de códigos, e, atendidas as condições estabelecidas pelas partes, é automaticamente executado (LACERDA, 2017).

Interessante salientar, outrossim, que essa tecnologia tem sido comparada com invenções como o motor a vapor ou a combustão, já que é potencialmente capaz de trazer benefícios a diversas atividades diárias e negociais (GATTESCHI et al, 2018, p. o1).

A vantagem na implementação dos contratos dentro da blockchain é que, além de não ser preciso a intermediação de terceiro, para obrigar uma das partes ao cumprimento de sua obrigação, por estar sendo processado apenas por computadores, "it can be formed as an objective authority over the agreement, automatically releasing money and fulfilling other conditions when the terms and conditions are met without the intervention of thirdparty intermediaries" (BHEEMAIAH, 2017, p. 140). ${ }^{5}$

A captação de dados e informações para implementação das obrigações é feita por meio dos componentes denominados "oráculos" (BASHIR, 2017, p. 200), que buscam dados externos necessários para controlar a execução dos termos contratuais. Os dados que são fornecidos pelos oráculos dependem do setor em que será aplicado o contrato, mas poderão ser, por exemplo, notícias diárias, previsão climática etc. O smart contract poderá assinar um oráculo e puxar os dados desejados, ou, as informações podem ser enviadas pelo próprio oráculo. De

5 Tradução livre: ele pode ser formado como uma autoridade objetiva sobre a avença, liberando o dinheiro automaticamente e cumprindo outras condições quando os termos e condições contratuais forem atendidos sem a intervenção de intermediários. 
todo modo, é indispensável que não sejam capazes de modificar os dados captados de fontes externas, garantindo, pois, confiabilidade (BASHIR, 2017, p. 206).

Existem diferentes tipos de oráculos, a exemplo, dos oráculos simples ou padrão, que são fornecidos por um terceiro confiável, centralizando todos os dados desejáveis e dos oráculos descentralizados, que são constituídos por mecanismo distribuído, podendo obter dados por meio de outro blockchain (ex.: retirar dados do blockchain utilizado por uma instituição que publica seus dados e permite o consumo por outrem) (BASHIR, 2017, p. 206).

As inovações contratuais sempre despertam na ciência jurídica dúvidas que envolvem questões técnicas e multidisciplinares, as quais, em regra, não são compreendidas facilmente pelo operador do Direito. Neste viés, os smart contratcs, pela sua complexidade técnica, que foge da formação do jurista, têm levantado inúmeras problemáticas jurídicas.

Questiona-se sobre a implementação das cláusulas contratuais mediante a realização de códigos computacionais, como impor a compreensão destas cláusulas pelos tribunais, bem como sobre a possibilidade de implementar por meio de códigos a resolução dada à demanda judicial e como tornar o código legível a pessoas e não somente a máquinas e programadores (BASHIR, 2017, p. 200).

A proteção de dados ganha relevância também, porque, diferente do que ocorre na celebração de contratos tradicionais, em transações virtuais, o contratante "deixa uma marca, um pedaço dela, isto é, suas informações, que a outra pessoa poderá utilizar, além da relação contratual que foi estabelecida" (LÔBO, 2011, p. 34).

Sobretudo em se tratando de smart contratcs em blockchain, cuja essência está, justamente, no fato de que os dados não poderão ser apagados ou modificados após inseridos no sistema. Uma vez captados pelos “oráculos”, ou mesmo inserido, espontaneamente, pelas partes contraentes, os dados, sejam pessoais ou não, estarão vinculados à tecnologia blockchain.

Relembre-se, outrossim, como explica BASHIR (2017, p. 206), que uma blockchain poderá retirar dados de outra, sendo perfeitamente possível a troca de dados pessoais. Isto, porém, poderá ocorrer sem o consentimento do titular deste, violando, pois, o seu direito fundamental à proteção de seus dados pessoais.

Vale destacar, outrossim, a possibilidade de erros em programação, em máquinas e erros de transmissão. Smart contracts, formulados estritamente em técnicas de programação, não estão alheios a problemas técnicos. Como ressalta LÔBO (2011, p. 35-38), "o programa não é um ser animado, mas um objeto manipulável pela empresa, que previamente definiu os critérios para aceitação ou recusa", pois, "atrás das máquinas e dos programas estão pessoas". Assim, não há como afastar a ocorrência de falhas, nem mesmo nos mais aprimorados sistemas computacionais.

Além disso, a possibilidadedeanulaçãodeum contratointeligenteviciado,étecnicamente questionável, mesmo diante de decisão judicial, pois, como revelado anteriormente, tratam-se de programas computacionais que se caracterizam pela capacidade de auto executabilidade e obrigatoriedade, isto é, uma vez satisfeitas as condições previstas pelos contraentes, um código computacional promoverá a execução dos termos contratuais, tornando-o irreversível.

Todas estas implicações jurídicas decorrentes da execução dos smart contracts não encontram no ordenamento brasileiro respostas prontas, exatamente pela complexidade técnica que envolve a temática, a qual não consegue ser acompanhada pela atividade legislativa e agrava a insegurança jurídica no âmbito dos negócios.

Contudo, é sabido que o direito contratual brasileiro é permeado por princípios jurídicos que orientam e acima de tudo, suprem lacunas legislativas em relação à formação das avenças, o cumprimento e a resolução destas, de modo que, torna-se imprescindível a análise dos smart contracts sob a ótica das normativas principiológicas. 
Assim, fazendo um recorte metodológico para viabilização da pesquisa, destacase, nesse estudo, a análise dos smart contracts à luz do princípio da função social dos contratos, corolário do direito dos contratos modernos, buscando verificar a possibilidade de implementação destes contratos inteligentes no Brasil.

\section{A FUNÇÃO SOCIAL DO SMART CONTRACT}

Para que possam ser reconhecidos perante o sistema jurídico nacional, os smart contracts devem respeitar todas as normas gerais e princípios estabelecidos para regulação dos negócios jurídicos, especialmente, enquanto o sistema carece de leis específicas para tutela de suas peculiaridades. Nesse sentido:

\footnotetext{
Não se pense, todavia, que os novos métodos alterem os princípios informadores dos contratos; provocam apenas a formação de normas que dão trato específico às peculiaridades que surgem. As disposições gerais e as aplicáveis à formação dos contratos, destinam-se igualmente às diferentes formas de convenções (NADER, 2015, p. 569).
}

Os princípios ganham relevância na discussão que se propõe, porque são necessários para o enfrentamento de eventuais lacunas legislativas face ao cenário de constante inovações tecnológicas e dinamicidade das relações jurídicas negociais, que não conseguem ser acompanhadas pela atividade legislativa.

Sem adentrar ao mérito da problemática que contorna a (des)necessidade da promulgação de novas leis para tutela desse novo meio contratual, pretende-se, neste tópico, abordar a aplicação do princípio da função social dos contratos aos smart contratcs, a fim de identificar se existem obstáculos a sua implementação a par do ordenamento jurídico brasileiro.

Em primeiro lugar, tem-se que o princípio da função social dos contratos, desenvolvido no século XX, foi positivado expressamente, pela primeira vez, no art. 421, do Código Civil, promulgado em 2002 (PEREIRA, 2017), sendo responsável por promover a proteção dos interesses sociais e do bem-estar coletivo no âmbito privado.

Trata-se de compreender que o contrato integra e altera a realidade social, produzindo efeitos não apenas entre as partes, mas também sobre terceiros que possam ser atingidos pelos efeitos extracontratuais. Embora não se sobreponha aos demais princípios que regem os contratos, tal como força obrigatória e relatividade de efeitos, a função social limita a autonomia da vontade dos contraentes face ao interesse social (PEREIRA, 2017).

Sabe-se que as relações contratuais clássicas, fundamentadas no liberalismo econômico, não admitiam que "[...] nenhuma força exógena poderia penetrar na economia do contrato. Mesmo que a sua execução fosse causa de ruína de um dos contratantes, mesmo assim teria de ser cumprido, porque a intervenção no contrato ofendia a liberdade de cada um" (PEREIRA, 2017).

O contrato, na concepção clássica, então, considerando-se a igualdade entre as partes, cumpria uma função meramente individual, qual seja, atender os interesses dos contratantes, limitados, tão somente, aos bons costumes e à ordem pública (LÔBO, 2016, p. 21).

Essa intangibilidade dos contratos, determinada pelo princípio do pact sunt servanda, regia as relações contratuais na vigência do Código Civil de 1916, face a ideologia liberalista. O Estado não poderia modificar os efeitos contratuais originalmente pactuados pelas partes, salvo se constatado a presença dos vícios de consentimento (NALIN, 2014, p. 116). 
Com o advento do Código Civil em 2002, diz-se que "houve um deslocamento de fulcro na vida contratual", pois, "[...] a necessidade de restabelecer o equilíbrio econômico das partes contratantes, rompido pelo crescimento do poder empresarial, fez recrudescer a ação estatal em detrimento da liberdade e da autonomia da vontade" (PEREIRA, 2017).

Em outras palavras, "mitiga-se o papel da vontade negocial para ganhar em dimensão o valor da pessoa humana, na figura do contratante e dos seus interesses patrimonial e existencial" (NALIN, 2014, p. 115).

É verdade que, o Estado não deve intervir sem medidas no processo econômico do país, porque, a própria Constituição Federal, promulgada em 1988, estabelece, em seu art. 170, que a ordem econômica nacional funda-se na valorização do trabalho humano e na livre iniciativa, devendo garantir existência digna a todos, conforme os ditames da justiça social.

Todavia, o ente público, pelo mesmo dispositivo constitucional, deve garantir que o desenvolvimento econômico seja abalizado pelos princípios da soberania nacional, da propriedade privada, da função social da propriedade, da livre concorrência, da defesa do consumidor, da defesa do meio ambiente, da redução das desigualdades regionais e sociais, da busca do pleno emprego e do tratamento favorecido para empresas de pequeno porte (BRASIL, 1988).

Assim, compreende-se que, o Estado, embora preserve a livre iniciativa e a livre concorrência, "[...] não pode permitir que em nome da liberdade negocial que a força econômica privada seja desviada para empreendimentos abusivos, incompatíveis com o bem-estar social e com os valores éticos cultivados pela comunidade" (THEODORO JR, 2014, s.p.).

É dizer: "a função individual do contrato permanece, mas é conformada à função social” (LÔBO, 2016, p. 22), de modo que, o Estado tem legitimidade para intervir, em termos contratuais, da seguinte forma:

na formação do contrato, impondo às partes celebrá-lo ainda contra sua vontade e contra seus interesses; estabelecendo cláusulas obrigatórias em muitas avenças que interessam de perto a economia popular; e supervisionando a execução ao dotar o Poder Judiciário de instrumental suficiente para intervir no sentido de restabelecer a justiça comutativa, sempre que uma das partes se avantaje à outra, procurando obter do jogo das convenções aquele lucro "maior da marca" a que o mestre Orosimbo Nonato se referia (PEREIRA, 2017).

Também "em nome do princípio da função social do contrato se pode, v.g., evitar a inserção de cláusulas que venham injustificadamente a prejudicar terceiros ou mesmo proibir a contratação de determinado objeto, em razão do interesse maior da coletividade" (PEREIRA, 2017, s.p.). E mais: "o contrato poderá ter seus efeitos econômicos mitigados pelo juiz, perdendo a liberdade contratual o seu caráter dogmático e absoluto", sendo que, "tal modificação operacionalizada pelo juiz ocorrerá por meio da revisão do preço ou por meio da resolução do contrato, por causa da excessiva onerosidade que atinge a prestação ou a base contratual" (NALIN, 2014, p. 117).

Importa mencionar que não há uma definição absoluta para o princípio da função social dos contratos, sendo adaptada conforme a ideologia seguida pelo autor e variando desde

[...] à abrangência dos efeitos do contrato (como contraponto ao princípio clássico da relatividade), à adequação que haveria de existir entre o instrumento (contrato) utilizado e o fim a que o mesmo se presta e à compreensão dos pactos tendo em visto o meio/contexto social em que estão inseridos (DAHITEN, A.; DAHITEN, B., 2014, p. 142). 
Em revisão bibliográfica apurada, NALIN (2011, p. 841) destaca que o princípio da função social relaciona-se "ora à quebra do individualismo, ora à cláusula geral de solidariedade, tendo em vista a igualdade substancial, a tutela da confiança dos interesses envolvidos e do equilíbrio das parcelas do contrato".

Assim, das variações interpretativas dadas à função social do contrato, BELLOIR e POSSIGNOLO (2017, p. 39-45) extraem, em síntese, as seguintes teorias: a) a função social como limite da liberdade contratual, sendo que a autonomia da vontade passa a orientar-se pela proteção dos interesses sociais. Por este viés, a lesão, o estado de perigo, a resolução por onerosidade excessiva, são institutos jurídicos fundamentados na função social dos contratos; b) a função social integra o contrato e promove uma redefinição em seu conceito, apresentando como uma meta e não elemento limitador da vontade das partes e c) a função social mitiga a relativização dos efeitos contratuais, ao passo que, para além de efeitos entre as partes contraentes, deve-se atentar para a repercussão externa, isto é, aos terceiros atingidos pelo instrumento da vontade.

Registra-se, ademais, que na jurisprudência brasileira, a função social dos contratos interpretada de acordo com a casuística levada à análise pelas partes, sendo comumente aposta como cláusula geral que serve para limitação da vontade das partes (pacta sunt servanda) (STJ, AgIn no AResp 1214641/AM, 2018), equalizando a relação de desigualdade preexistente entre consumidor e fornecedor (STJ, Resp 169978o/SP, 2018), possibilitando a revisão contratual em casos de excessiva onerosidade (STJ, AgRg no REsp 1363814/PR, ${ }^{2016)}$, em como permitindo a redução de valores exorbitantes fixados à título de multa contratual (STJ, REsp 1580278/SP, 2018).

Não constitui objeto deste ensaio aprofundar-se nas inúmeras concepções do princípio da função social. Para o estudo proposto, apoiando-se na interpretação jurisprudencial, partese da premissa de que o princípio da função social determina os motivos que levam as partes a contratarem e estabelece limite aos interesses reais da parte, permitindo, dentre outras coisas, a modulação dos efeitos do contrato, seja em relação ao próprio contratante, seja em relação a terceiros que possam ser afetados.

Com efeito, partindo-se desta premissa, questiona-se como se daria a aplicação do princípio da função social aos smart contracts, vez que, como comentado no tópico anterior, caracterizam-se pela autoexecutabilidade, obrigatoriedade e irretroatividade.

Em primeiro lugar, considera-se que o conceito do smart contract, por si só, apresentase em sentido contrário a todo conteúdo normativo do princípio da função social dos contratos. Veja-se que, sendo autoexecutável, obrigatório e capaz de afastar qualquer interferência externa, não seria tecnicamente possível limitar os interesses privados das partes, para atendimento dos interesses sociais, tampouco, a modulação dos efeitos produzidos pelos termos da avença, exatamente porque, uma vez celebrado, o contrato produzirá seus efeitos automaticamente, sem possibilidade de reversão da medida, pelo mesmo contrato.

Não se poderia cogitar, inclusive, na obtenção de ordem judicial para modificar, ou mesmo resolver o contrato celebrado em blockchain. De um lado, porque, a tecnologia é criada, justamente, para não permitir a reversibilidade dos comandos programados e de outro, porque, uma decisão judicial, nos termos como concebida atualmente (comado escrito), não conseguiria atuar limitando um código computacional autoexecutável, no qual fora desenvolvido o smart contract.

Sobre a inocuidade de decisão judicial em face dos smart contracts, relembre-se também que, a tecnologia blockchain, que propõe maior confiança e segurança às partes contraentes, é programada para que fatores externos não alterem a lógica contratual estabelecida originariamente. Logo, uma ordem judicial, em regra, não poderia alterar quaisquer dos termos contratuais. 
Acrescente-se, outrossim, que esse cenário de insegurança jurídica se agrava sobremaneira em se tratando de relações de consumo, uma vez que diversas garantias concedidas aos consumidores tendem a desaparecer na execução dos smart contracts.

É o caso, por exemplo, da garantia de revisão contratual na hipótese de fatos supervenientes que torne uma obrigação consumerista excessivamente onerosa. Mesmo diante de manifesto desequilíbrio contratual, tendo sido implementada a relação de consumo mediante smart contract, não seria possível revê-la para trazer equilíbrio às partes, ocasionando, além de violação ao princípio da função social dos contratos, flagrante violação a direito básico do consumidor, garantido pelo art. 6.o, inc. V, do Código de Defesa do Consumidor.

Como consequência, é preciso considerar que, "o contrato desviado de sua função social não ficará livre de uma sanção jurídica, pois sua prática incursiona pelo terreno da ilicitude" (THEODORO JR, 2014). Neste sentido, também, o enunciado 431 da V Jornada de Direito Civil "a violação do art. 421 conduz à invalidade ou à ineficácia do contrato ou de cláusulas contratuais (CONSELHO DA JUSTIÇA FEDERAL, 2012).

A função social do contrato apresenta-se perante o sistema jurídico nacional como norma de ordem pública, de modo que, tal como consubstanciado pelo art. 2.035 do Código Civil, nada prevalecerá, se em sentido contrário ao que se dá a norma principiológica (FACHIN, 2011, p. 169-170).

Todas estas casuístas apresentadas demonstram que a implementação dos smart contracts em tecnologia blockchain, no Brasil, encontra obstáculos em face do princípio da função social, em decorrência de suas próprias características, quais sejam: autoexecutabilidade, obrigatoriedade e irretroatividade.

No entanto, a ciência jurídica não poderá omitir-se em relação aos smart contracts, em verdadeira ascensão no aspecto contratual em todo o mundo, tampouco o sistema jurídico brasileiro poderá impedir a sua entrada ou obstar a sua funcionalidade em território nacional, porquanto inexistem fronteiras para a tecnologia no mundo globalizado.

Por esta razão, compreende-se que a comunidade científica deve impreterivelmente debruçar-se ao tema, empreendendo esforços para aliar, de forma concreta, o desenvolvimento tecnológico aos negócios contratuais, em respeito às garantias jurídicas presentes no ordenamento brasileiro.

\section{CONSIDERAÇÕES FINAIS}

Os smart contracts apresentam-se como produto da interação entre tecnologia e Direito, na medida em que implica em alterações substanciais em relação ao modo de contratar e principalmente, quanto ao modo de execução dos contratos.

Em síntese, contratos inteligentes são aqueles criados por meio de códigos computacionais, cuja execução ocorre automaticamente após a implementação da condição estipulada pelas partes. São características dos smart contracts: autoexecutabilidade; autoaplicáveis ou obrigatórios, porque nada poderá obstar a sua produção de efeitos; descentralizados e independentes, uma vez que não exigem a intermediação do negócio por um terceiro, dentre outras elencadas ao longo da pesquisa.

Recentemente, os códigos que compõem o smart contract passam a ser armazenados em blockchain - aplicação tecnológica que permite o armazenamento de transações em cadeia de blocos - e, implementada a condição estabelecida pelas partes, ter-se-á, automaticamente, a produção dos efeitos jurídicos contratuais, de modo irretroativo, e sem que qualquer força externa possa interferir. 
As inúmeras questões técnicas e multidisciplinares que entornam os smart contracts dificultam, sobretudo, a compreensão das implicações jurídicas pelos profissionais do Direito. Além disso, agrava-se o cenário de insegurança jurídica a dinamicidade das inovações tecnológicas que não consegue ser acompanhada pelo Poder Legislativo brasileiro, inexistindo, pois, normativas específicas para a tutela dos conflitos jurídicos inéditos oriundos da aplicação dos smart contracts.

Sem adentrar à questão de (des)necessidade de promulgação de legislação específica para regulamentação dos smart contracts, a pesquisa apresenta uma análise sobre o princípio da função social dos contratos aplicados aos contratos inteligentes, considerando que, os princípios jurídicos contratuais são indispensáveis para elaboração e execução de quaisquer contratos, especialmente, aqueles que não encontram guarida específica na legislação.

Neste sentido, compreende-se que o princípio da função social dos contratos, positivado no art. 421 do Código Civil de 2002, busca proteger os interesses coletivos no âmbito privado. Os contratos, que outrora deveriam cumprir função meramente individual, passam a assumir uma função coletiva, com a limitação da autonomia da vontade dos contraentes, em prol do valor da pessoa humana. Trata-se de compreender, em verdade, que o contrato, elaborado e executado em sociedade, produz efeitos para além das partes, e por isso, deve considera-las.

A norma principiológica busca fundamento na própria Constituição Federal de 1988, especialmente no art. 170, que estabelece princípios balizadores da ordem econômica nacional e permite compreender que, o Estado deve preservar a livre iniciativa e concorrência, mas não poderá permitir práticas abusivas e o ajuste de condições que afastem o bem-estar coletivo.

Por meio do princípio da função social dos contratos, permite-se impedir a inserção de cláusulas contratuais, a respectiva revisão, bem como a modulação de efeitos dos contratos em decisões judiciais, e inclusive a própria resolução de contrato (v.g. em casos de onerosidade excessiva).

Contudo, na análise dos smart contracts compreende-se que, as prerrogativas conferidas pelo princípio da função social dos contratos são afastadas. Mesmo em casos de flagrante violação legal, com prejuízo à coletividade, não é possível que uma decisão judicial obste a produção de efeitos de um smart contract, pois, tão logo realizada a condição estabelecida pelas partes, o contrato será implementado. A tecnologia blockchain, nos quais serão instituídos os termos da avença, deve garantir, inclusive, que nenhuma força externa possa interferir na execução contratual.

Do mesmo jeito, não se vislumbra possível a resolução de um contrato inteligente, mesmo diante de uma decisão judicial, exatamente porque, a tecnologia é criada para não permitir a reversibilidade dos comandos programados.

Dessa forma, entende-se que a implementação dos smart contracts no Brasil encontra obstáculos face ao conteúdo do princípio da função social dos contratos, exigindo-se dos estudiosos jurídicos maior atenção ao assunto, tendo em vista tratar-se de modelo negocial presente na sociedade hodierna e que não poderá ser evitado pelo Estado, especialmente, no contexto globalizado em que se vive atualmente, quando a tecnologia ultrapassa qualquer fronteira territorial, em um único instante. 


\section{REFERÊNCIAS}

AGUIAR JR, Ruy Rosado de. Conselho de Justiça Federal. In: V JORNADAS DE DIREITO CIVIL. 2012. Brasília. Anais Eletrônico... Brasília: CJF, 2012. Disponível em: <http://www.cjf.jus.br/ cjf/corregedoria-da-justica-federal/centro-de-estudos-judiciarios-1/publicacoes-1/jornadascej/vjornadadireitocivil2012.pdf >. Acesso em: 22 abr. 2018.

BASHIR, Imran. Mastering blockchain: distributed ledgers, decentralization and smart contracts explained. Packt: Birmigham, UK, 2017.

BAUMAN, Zygmunt. Globalização: as consequências humanas. Tradução por Marcus Penchel. Rio de Janeiro: Zahar, 1999.

BECK, Ulrich. La sociedad del riesgo global. España: Siglo Veintiuno, 2002.

BELLOIR, Arnaud Marie Pie; POSSIGNOLO, André Trapani Costa. Ensaio de classificação das teorias sobre a função social do contrato. Revista Brasileira de Direito Civil - RBDCivil, Belo Horizonte, v. 11, p. 37-56, jan./mar. 2017. Disponível em: <https://rbdcivil.ibdcivil.org.br/ rbdc/article/view/7/6>. Acesso em: 02 out. 2018.

BHEEMAIAH, Kariappa. The blockchain alternative: rethinking macroeconomic policy and economic theory. Paris, France, 2017.

BRANDÃO, Fernanda Holanda V; VASCONCELOS, Fernando A. As redes sociais e a evolução da informação no século XXI. Direito e Desenvolvimento, João Pessoa, v. 4, n. 7, p. 125-144, jan./ jun. 2013. Disponível em: <https://periodicos.unipe.br/index.php/direitoedesenvolvimento/ article/view/225/207>. Acesso em: 20 abr. 2018.

BRASIL. Constituição Federal de 1988. Brasília, Diário Oficial, 1988. Disponível em: <http:// www.planalto.gov.br/ccivil_03/constituicao/constituicaocompilado.htm>. Acesso em: 21 abr. 2018.

Superior Tribunal de Justiça. Agravo em Recurso Especial no 1.214.641. Rel. Ministro Marco Aurélio Bellizze. Terceira Turma. Julgado em 13/03/2018. Disponível em: $<$ https://ww2.stj.jus.br/processo/revista/inteiroteor/?num_registro=201703096405\&dt publicacao=26/03/2018>. Acesso em: 02 out. 2018.

Superior Tribunal de Justiça. Recurso Especial n.o 169978o/SP. Rel. Ministro Marco Aurélio Bellizze. Terceira Turma. Julgado em 11/o9/2018. Disponível em: <https://ww2.stj.jus. $\mathrm{br} / \mathrm{processo} / \mathrm{revista} /$ documento $/$ mediado $/$ ?componente=ATC\&sequencial $=84506191 \&$ num registro $=201702389420 \&$ data $=20180917 \&$ tipo $=51 \&$ formato $=P D F>$. Acesso em: 02 out. 2018.

. Superior Tribunal de Justiça. Agravo Regimental em Recurso Especial n.o 1363814/ PR. Rel. Ministro Moura Ribeiro. Julgado em 17/12/2015. Disponível em: <https://ww2.stj.jus. $\mathrm{br} /$ processo $/ \mathrm{revista} /$ documento $/$ mediado $/$ ?componente=ATC\&sequencial $=48641103 \&$ num registro $=201200775677 \&$ data $=20160203 \&$ tipo $=91 \&$ formato $=\mathrm{PDF}>$. Acesso em: 02 out. 2018. 
Superior Tribunal de Justiça. Recurso Especial n.o 1580278/SP. Rel. Ministra Nancy Andrighi. Julgado em 21/o8/2018. Disponível em: <https://ww2.stj.jus.br/ processo $/ \mathrm{revista} /$ documento $/$ mediado $/$ ?componente $=$ ATC \& sequencial $=86075360 \&$ num registro=201600212683\&data $=20180903 \&$ tipo $=5 \&$ formato=PDF $>$. Acesso em: 02 out. 2018.

CAPPELA, Juan Ramón. Os cidadãos servos. Porto Alegre: Sergio Antonio Fabris, 1998.

DAHINTEN, Augusto Franke; DAHITEN, Bernardo Franke. O Princípio da Função Social e o Contrato de Seguro: algumas implicações práticas à luz da jurisprudência. Revista de Direito Civil Contemporâneo, v. 9, p. 141-158, 2016. Disponível em: <http://ojs. direitocivilcontemporaneo.com/index.php/rdcc/article/view/179>. Acesso em: 02 out. 2018.

EFING, Antônio Carlos; FREITAS, Cinthia Obladen de Almendra (org). Direito e questões tecnológicas: aplicados no desenvolvimento social. V. 2. Curitiba: Juruá, 2012.

FREITAS, Cinthia Obladen Almendra; PARCHEN, Charles Emmanuel. Computação em nuvem e aspectos jurídicos da segurança da informação. Revista Jurídica Cesumar, v. 13, n. 1, 2013. p. 346. Disponível em: <http://periodicos.unicesumar.edu.br/index.php/revjuridica/ article/view/2705/1905>. Acesso em: 22 abr. 2018.

FACHIN, Luiz Edson. Contratos e ordem pública. In: MIRAGEM, B.; MARQUES, C. L. (Org.). Doutrinas Essenciais de Direito do Consumidor. São Paulo: Revista dos Tribunais, v. 3, 2011.

FREITAS, C. O. A.; BATISTA, O. H. S. Neuromarketing e as Novas Modalidades de Comércio Eletrônico (m-s-t-f-commerce) frente ao Código de Defesa do Consumidor. Derecho y Cambio Social, v. 42, p. 3, 2015. Disponível em: <https://www.derechoycambiosocial.com/revistao42/ NEUROMARKETING_E_AS_NOVAS_MODALIDADES_DE_COMERCIO_ELETRONICO. pdf>. Acesso em: 17 abr. 2018.

GATTESCHI, Valentina; ORCID, Fabrizio Lamberti; ORCID, Claudio Demartini; PRANTEDA, Chiara; SANTAMARÍA, Victor. Blockchain and Smart Contracts for Insurance: Is the Technology Mature Enough? Future Internet, v. 10, fev. 2018. Disponível em: <http://www. mdpi.com/1999-5903/10/2/20/htm>. Acesso em: 04 abr. 2018.

GIDDENS, Anthony. As consequências da modernidade. Tradução por Raul Fiker. São Paulo: Unesp, 1991.

LACERDA, Eduardo. A segunda era da Internet, as infraestruturas de assinaturas digitais e os entes confiáveis KSI, PKI e Blockchain Permissionado. Instituto Nacional de Tecnologia da Informação, Brasília, 2017. Disponível em: <http://www.iti.gov.br/images/ repositorio/publicacoes_tecnicas/_A_segunda_era_da_Internet_as_infraestruturas_de_ assinaturas_digitais_e_os_entes_confi\%C3\%Arveis_KSI_PKI_e_Blockchain_Permissionado. pdf>. Acesso em: 16 abr. 2018.

LEÃO, Luana da Costa. As relações negociais eletrônicas. Revista de Direito Empresarial, v. 6, nov-dez, 2014. Disponível em: < https://bdjur.stj.jus.br/jspui/handle/2011/83147>. Acesso em: 02. out. 2018. 
LÔBO, Paulo. Direito civil: contratos. 3. São Paulo: Saraiva, 2016. Recurso online.

MARQUES, Verônica Teixeira; OLIVEIRA, Liziane Paixão Silva; SÁTIRO, Guadalupe Souza. O reconhecimento jurídico do direito ao desenvolvimento como um direito humano e sua proteção internacional e constitucional. Direito e Desenvolvimento, João Pessoa, v. 7, n. 13, p. 170-189. Disponível em: <https://periodicos.unipe.br/index.php/direitoedesenvolvimento/ article/view/307/289>. Acesso em: 20 abr. 2018.

NADER, Paulo. Curso direito civil: contratos. v.3, 8.ed. Rio de Janeiro: Forense, Ebook. 2015.

NALIN, Paulo. A força obrigatória dos contratos no Brasil: uma visão contemporânea e aplicada à luz da jurisprudência do Superior Tribunal de Justiça em vista dos princípios sociais dos contratos. Revista do Instituto Brasileiro de Direito Civil - IBDCivil, v. 1, 2014. p. 115. Disponível em: <https://rbdcivil.ibdcivil.org.br/rbdc/article/view/133/129>. Acesso em: o6 maio 2018.

. A função social do contrato no futuro Código Civil brasileiro. In: TEPEDINO, Gustavo; FACHIN, Luiz Edson. Doutrinas essenciais: obrigações e contratos. São Paulo: Revista dos Tribunais, 7 V. 2011.

PEREIRA, Caio Mario da Silva. Instituições de direito civil, v.3 contratos. Atual. Caitlin Mulholland. 21. ed. Rio de Janeiro: Forense, 2017. Ebook.

THEODORO JÚNIOR, Humberto. O contrato e sua função social. 4. ed. Rio de Janeiro: Forense, 2014. E-book.

UNIÃO EUROPEIA. Regulamento 2016/679 do Parlamento europeu e do Conselho de 27 de abril de 2016. Regulamento Geral sobre a Proteção de Dados. Jornal Oficial da União Europeia, Bruxelas, 2016. Disponível em: <https://eur-lex.europa.eu/legal-content/PT/TXT/ HTML/?uri=CELEX:32016Ro679\&from=PT>. Acesso em: 05 maio 2018. 